\section{BRAZIULIAN JOURNAL}

OF MEDICAL AND BIOLOGICAL RESFARCH

www.bjournal.com.br
ISSN 0100-879X

Volume 44 (7) 606-728 July 2011

BIOMEDICAL SCIENCES

AND

CLINICAL INVESTIGATION

Braz J Med Biol Res, July 2011, Volume 44(7) 671-681

doi: 10.1590/S0100-879X2011007500067

Aging alters the production of iNOS, arginase and cytokines in murine macrophages

C.A. Cecílio, E.H. Costa, P.U. Simioni, D.L. Gabriel and W.M.S.C. Tamashiro

The Brazilian Journal of Medical and Biological Research is partially financed by

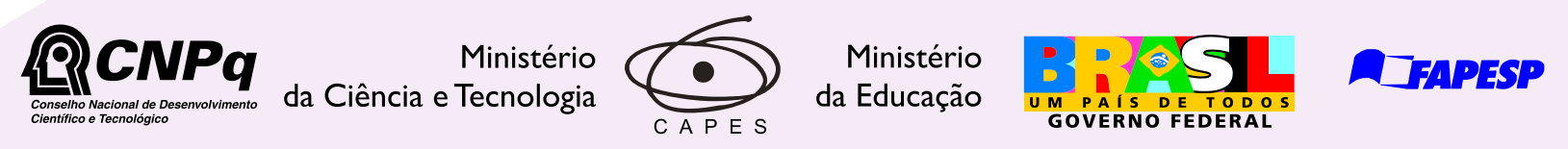

Institutional Sponsors
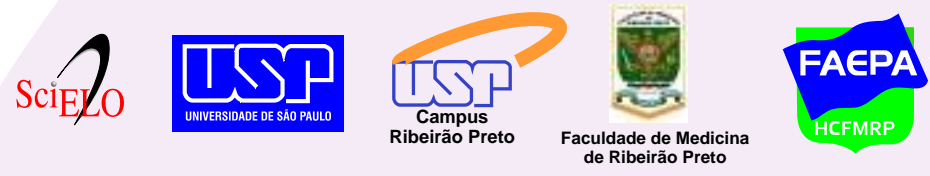

de Ribeirão Predic

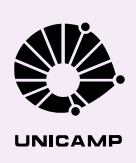

$\oplus$ SHIMADZU

GE Healthcare
Hotsite of proteomics metabolomics developped by:

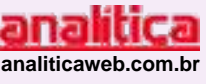




\title{
Aging alters the production of iNOS, arginase and cytokines in murine macrophages
}

\author{
C.A. Cecílio, E.H. Costa, P.U. Simioni, D.L. Gabriel and W.M.S.C. Tamashiro \\ Departamento de Genética, Evolução e Bioagentes, Instituto de Biologia, \\ Universidade Estadual de Campinas, Campinas, SP, Brasil
}

\begin{abstract}
The limited amount of information on the primary age-related deficiencies in the innate immune system led us to study the production of inducible nitric oxide synthase (iNOS), arginase, and cytokines in macrophages of young (8 weeks old) and old (72 weeks old) female BALB/c mice. We first evaluated iNOS and arginase inducers on peritoneal (PMФ) and bone marrowderived (BMMФ) macrophages of young BALB/c and C57BL/6 mice, and then investigated their effects on macrophages of old mice. Upon stimulation with lipopolysaccharide (LPS), resident and thioglycolate-elicited PM $\Phi$ from young mice presented higher iNOS activity than those from old mice (54.4\%). However, LPS-stimulated BMMФ from old mice showed the highest NO levels (50.1\%). Identical NO levels were produced by РМФ and ВМMФ of both young and old mice stimulated with interferon- $\gamma$. Arginase activity was higher in resident and elicited PMФ of young mice stimulated with LPS (48.8 and $32.7 \%$, respectively) and in resident PMФ stimulated with interleukin (IL)-4 (64\%). ВММФ of old mice, however, showed higher arginase activity after treatment with IL-4 (46.5\%). In response to LPS, PMФ from old mice showed the highest levels of IL-1 $\alpha(772.3 \pm 51.9 \mathrm{pg} / \mathrm{mL})$, whereas those from young mice produced the highest amounts of tumor necrosis factor (TNF)- $\alpha(937.2 \pm 132.1 \mathrm{pg} / \mathrm{mL})$. Only TNF- $\alpha$ was expressed in LPS-treated BMM $\Phi$, and cells from old mice showed the highest levels of this cytokine (994.1 \pm 49.42 $\mathrm{pg} / \mathrm{mL}$ ). Overall, these results suggest that macrophages from young and old mice respond differently to inflammatory stimuli, depending on the source and maturity of the cell donors.
\end{abstract}

Key words: Aging; iNOS; Arginase; Cytokines; Murine macrophages; Inflammatory stimuli

\section{Introduction}

Aging is accompanied by a reduced efficiency of the immune system, thus compromising the general health of older individuals (1-3). Although the age-dependent changes in the adaptive immune system are well documented, changes in the innate immune system have been poorly described. However, the interdependency of the adaptive and innate immune systems is becoming increasingly clear, since they appear to cooperate at various levels to ensure an efficient immune response against microbes and tumor cells (4). Thus, the malfunctions in one aspect of immunity may severely hinder the functioning of the whole immune system, especially in the elderly.

Cells of the immune system deal efficiently with microbes by producing antimicrobial molecules, as well as free radicals (for a review, see Ref. 5). Nitric oxide (NO) is a toxic gas produced by the action of the enzyme family nitric oxide synthase (NOS), which converts L-arginine to citrulline and NO $(6,7)$. Cytokines such as interferon-y
(IFN- $\mathrm{Y}$ ) and tumor necrosis factor- $\alpha$ (TNF- $\alpha$ ), as well as bacterial lipopolysaccharide (LPS), are responsible for the expression of an inducible form of NOS (iNOS) and the generation of large amounts of $\mathrm{NO}$ in neutrophils and macrophages (8-12). Under certain circumstances, NO reacts with superoxide anion to form peroxynitrite, a potent oxidizing molecule that contributes to tissue injury during inflammatory processes (13).

Arginase also metabolizes L-arginine to ornithine and urea; it exists in two forms, arginase 1 and 2 (Arg 1 and Arg 2) (14-16). These arginase isoforms differ in terms of tissue distribution, subcellular localization, immunologic cross-reactivity, and physiologic functions. During early developmental stages, Arg 1 is expressed predominantly in the peripheral nervous system, the digestive system and in tissue leukocytes, whereas Arg 2 is found only in the intestines (16). Cytosolic Arg 1 is involved in ammonia degradation in the urea cycle, and its absence in deficient

Correspondence: W.M.S.C. Tamashiro, Departamento de Genética, Evolução e Bioagentes, Instituto de Biologia, UNICAMP, Caixa Postal 6109, 13083-970 Campinas, SP, Brasil. Fax: +55-19-3521-6276. E-mail: wirlatam@unicamp.br

Received September 25, 2010. Accepted May 13, 2011. Available online May 27, 2011. Published July 25, 2011. 
patients leads to hyperammonemia. Arg 2, on the other hand, is a mitochondrial isoform and is mainly involved in ornithine biosynthesis, with its absence not resulting in any phenotypic deficiency (17). The arginases are also involved in the generation of polyamines, e.g., putrescine, spermidine, and spermine, which are important for the regulation of cell proliferation, cell differentiation, and cell death $(15,18)$.

Macrophages may be able to express both arginase isoforms in response to LPS, although the literature is controversial in this regard $(19,20)$. Another way of inducing arginase production is the stimulation of macrophages with Th2 cytokines such as interleukin-4 (IL-4), IL-10, and IL-13. These murine macrophages up-regulate the expression of Arg 1, but not that of Arg 2 (21). On the other hand, inflammatory cytokines such as IFN- $\gamma$ and TNF- $\alpha$, alone or in combination with LPS, are able to induce iNOS. It has been suggested that the production of iNOS is usually accompanied by arginase expression, and that this arginase may contribute to buffering the overproduction of toxic NO (17). However, it is unclear whether this balance is maintained with aging. In the present study, we analyzed iNOS and arginase activities, as well as cytokine production, in macrophages from young and old mice submitted to different stimuli. Our results suggest that significant changes take place in macrophages of old mice, depending on the source and maturity of the cell donors.

\section{Material and Methods}

\section{Animals}

Four-week-old female BALB/c and C57BL/6 mice were supplied by the Multi-Institutional Center for Biological Investigation (CEMIB) of the University of Campinas (UNICAMP). Mice were housed under specific pathogenfree conditions in the animal facilities of the Department of Genetica, Evolution and Bioagents, Institute of Biology, UNICAMP, and were provided with autoclaved food and water ad libitum. Both mouse strains were used at 8 weeks of age. Seventy-two-week-old BALB/c mice were also used. The study was approved by the institutional Committee for Ethics in Animal Experimentation (Protocol No. 450-1).

\section{Reagents \\ LPS from Escherichia coli and thioglycolate medium were purchased from Difco Laboratories (USA); RPMI 1640, HEPES, Hank's balanced salt solution (HBSS) containing $\mathrm{Ca}^{2+}$ and $\mathrm{Mg}^{2+}(\mathrm{H} 6648)$, 2-mercaptoethanol, L-arginine, urea, sulfanilamide, $N$-(1-naphthyl) ethylene- diamine dihydrochloride, Triton-X, aprotinin, antipain, and $\alpha$-isonitrosopropiophenone (ISPF) were purchased from Sigma-Aldrich Chemical (USA); IL-4 and IFN- $\gamma$ were purchased from R\&D (USA) and from Genzyme (USA), respectively.}

\section{Cells}

Macrophages were isolated from the peritoneal cavity of naive $(N=15)$ or thioglycolate-treated mice $(N=5)$, as described elsewhere (22). Peritoneal cells were cultured at a density of $2 \times 10^{5}$ cells in 96-well plates, $1 \times 10^{6}$ cells in 24-well plates or $5 \times 10^{6}$ cells in 6 -well plates in RPMI-1640 medium containing 10\% heat inactivated fetal calf serum (FCS; Brazil) for $2 \mathrm{~h}$ at $37^{\circ} \mathrm{C}$ in $5 \% \mathrm{CO}_{2}$. Non-adherent cells were washed out, and adherent cells were cultured in the presence of appropriate stimuli as indicated below.

Bone marrow-derived macrophages were differentiated from precursor cells in a modification of the procedure described by Munder et al. (21). Briefly, bone marrow cells were obtained by flushing the femurs of mice $(N=5)$. They were cultured in 6 -well plastic plates at a density of $5 \times 10^{6}$ cells/well, in $3 \mathrm{~mL}$ RPMI-1640 medium containing $10 \%$ heat inactivated FCS, $5 \%$ horse serum, and a $30 \%(\mathrm{v} / \mathrm{v})$ concentration of L929 fibroblast culture supernatants, as a source of colony stimulating factors (CSFs) to drive cell differentiation. On day 4, the plates were swirled vigorously, and $2.5 \mathrm{~mL}$ of the medium was discarded and replaced with fresh CSF-containing medium. The adherent cells were harvested on day 8 with cold saline, sedimented by centrifugation and then cultured at a density of $2 \times 10^{5}$ in $200 \mu \mathrm{L}$ medium in 96well plates, of $1 \times 10^{6}$ in $1 \mathrm{~mL}$ medium in 24-well plates or of $5 \times 10^{6}$ in $3 \mathrm{~mL}$ medium in 6-well plates.

The strain of Leishmania major was supplied by Dr. Fernando de Queiróz Cunha (Faculdade de Medicina de Ribeirão Preto, USP, Brazil) and grown in our laboratory by passages at 5-7-day intervals in an Iscove medium containing $10 \mathrm{mM}$ HEPES, $2 \mathrm{~g} / \mathrm{L}$ sodium bicarbonate, $25 \mathrm{mg} / \mathrm{L}$ gentamicin and 20\% FCS. For the phagocytosis assays, the promastigotes (stationary phase) were collected from culture flasks, transferred to centrifuge tubes and centrifuged at $200 \mathrm{~g}$ for $20 \mathrm{~min}$. The pellet was resuspended in incomplete RPMI medium and the parasites were pelleted at $200 \mathrm{~g}$ for $20 \mathrm{~min}$. The final sediment was suspended in complete RPMI and counted in a Neubauer chamber, and the suspension was adjusted to $3 \times 10^{6}$ forms $/ \mathrm{mL}$.

Thymocytes of BALB/c or C57BL/6 mice were treated with dexamethasone to induce apoptosis as described by Fadok et al. (23). Briefly, the thymuses were collected aseptically and placed on sterile Petri dishes containing incomplete RPMI. The organs were macerated and the suspension obtained was filtered through a sieve to separate cell debris. After centrifugation of $200 \mathrm{~g}$ for $10 \mathrm{~min}$, cells were resuspended in a culture medium. An aliquot of the suspension was labeled with anti-CD3 (clone 2C11)-fluorescein for analysis by flow cytometry (FACScalibur, USA), and $81-99.7 \%$ of $\mathrm{CD}^{+}$cells were detected in three separate preparations. Cells were plated onto 6-well culture plates (Corning) at a density 
of $2 \times 10^{7}$ cells in $3 \mathrm{~mL} /$ well RPMI containing $10 \% \mathrm{FCS}$, $50 \mathrm{~mL} / \mathrm{L}$ gentamicin and $10 \mu \mathrm{M}$ dexamethasone, and incubated at $37^{\circ} \mathrm{C}$ in a humidified incubator with a $5 \%$ $\mathrm{CO}_{2}$ atmosphere for 15 to $18 \mathrm{~h}$. Apoptotic cells were then collected from culture plates by gentle pipetting, centrifuged at $200 \mathrm{~g}$ for $10 \mathrm{~min}$, resuspended in culture medium, and adjusted to a concentration of $5 \times 10^{6}$ cells $/ \mathrm{mL}$.

Zymosan was prepared from the cell wall of Saccharomyces cerevisiae. Briefly, $5 \mathrm{mg}$ baker's yeast (Fleischmann's Yeast; Fermix, Brazil) was transferred to a glass flask, which was filled with $150 \mathrm{~mL}$ sterile 0.15 $\mathrm{M}$ saline, and heated in a water bath at $100^{\circ} \mathrm{C}$ (Dubnoff bath; Marconi, Brazil) for $1 \mathrm{~h}$. Aliquots of $50 \mathrm{~mL}$ were separated and filtered through a funnel with sterile gauze, and centrifuged several times at $200 \mathrm{~g}$ for 10 min until the supernatants became clear. The particles were resuspended in $0.15 \mathrm{M}$ saline, adjusted to a concentration of $2 \times 10^{8} / \mathrm{mL}$ and kept at $-20^{\circ} \mathrm{C}$ until use. A 2-mL aliquot of the standard zymosan suspension was added to $200 \mu \mathrm{L}$ normal rabbit serum and incubated for $15 \mathrm{~min}$ at $37^{\circ} \mathrm{C}$ with occasional shaking. The reaction was stopped by reducing the temperature on an ice bath and by diluting the suspension in cold $0.15 \mathrm{M}$ saline. After centrifugation at $200 \mathrm{~g}$ for $5 \mathrm{~min}$ at $4^{\circ} \mathrm{C}$, the supernatant was discarded. Then, the zymosan was washed again in cold $0.15 \mathrm{M}$ saline and the sediment was resuspended in $2 \mathrm{~mL}$ HBSS (Sigma). The suspension was adjusted to a concentration of $10^{8}$ cells $/ \mathrm{mL}$.

\section{Cell cultures for the evaluation of NO production, arginase activity and cytokines}

Peritoneal (PMФ) and bone-marrow-derived (BMMФ) macrophages were cultured for $48 \mathrm{~h}$ in the presence of LPS (1 to $1000 \mathrm{ng} / \mathrm{mL}$ ), IFN-y (0.5 to $50 \mathrm{IU} / \mathrm{mL}$ ) and IL-4 $(0.1$ to $10 \mathrm{ng} / \mathrm{mL})$, alone or in combination. The supernatants were then harvested for the determination of $\mathrm{NO}$ and cytokine production. Cell extracts were used to measure arginase activity as described below. In some experiments, adherent cell monolayers were cultured simultaneously in the presence of IL-4 and LPS, as indicated in the figures.

NO production and arginase activity were also analyzed in $P M \Phi$ harvested from the peritoneal cavities of $\mathrm{BALB} / \mathrm{c}$ and $\mathrm{C} 57 \mathrm{BL} / 6$ mice, and cultured in the presence or absence of LPS, IL-4 and IFN- $\gamma$ after the phagocytosis of $L$. major, apoptotic lymphocytes and zymosan. Briefly, adherent cells from the peritoneal cavity of mice were seeded at a density of $1 \times 10^{6}$ cells $/ \mathrm{mL}$ in 24-well plates and cultured for $18 \mathrm{~h}$ with suboptimal doses of LPS (100 ng/mL), IL-4 (4 ng/mL) or IFN-ץ (5 IU $/ \mathrm{mL})$. After washing the cultures to remove the stimulus, opsonized zymosan $\left(5 \times 10^{6}\right)$, apoptotic lymphocytes $(5 \mathrm{x}$ $\left.10^{6}\right)$ or promastigotes of L. major $\left(3 \times 10^{6}\right)$ were added to culture wells and the plates were incubated for $3 \mathrm{~h}$ at $37^{\circ} \mathrm{C}$ in a $\mathrm{CO}_{2}$ incubator. After this period, free particles were removed by washing with incomplete medium, and cultures were re-incubated in complete RPMI medium for $48 \mathrm{~h}$ in a $\mathrm{CO}_{2}$ incubator. After this period, the supernatants were collected for the determination of nitrite, and macrophage monolayers were prepared to obtain cell extracts for the determination of arginase activity by conversion of L-arginine to urea.

\section{Measurement of NO}

$\mathrm{NO}$ was measured as nitrite in the supernatants of macrophage cultures using the Griess reagent, as described elsewhere (10). Briefly, each $50-\mu \mathrm{L}$ aliquot was mixed with $50 \mu \mathrm{L} 1 \%$ sulfanilamide, $0.1 \% N$-(1-naphthyl) ethylenediamine dihydrochloride, and $2.5 \% \mathrm{H}_{3} \mathrm{PO}_{4}$. Absorbance was measured at $540 \mathrm{~nm}$ in a microplate reader (Multiskan II, MS, Labsystem, Finland), and the concentration of nitrite in the samples was determined by comparison with a standard curve of sodium nitrite ( 5 to $320 \mu \mathrm{M}$ ).

\section{Determination of arginase activity}

Arginase activity was measured in cell lysates in the presence of urea, which is a conversion product of L-arginine, according to the procedure described by Corraliza et al. (24), with some modifications. Briefly, cells in 96-well flat-bottomed plastic plates were incubated with $50 \mu \mathrm{L} /$ well lysis solution $(0.1 \%$ Triton X-100 solution containing $5 \mu \mathrm{g}$ aprotinin and $5 \mu \mathrm{g}$ antipain) in a shaker, for $30 \mathrm{~min}$, at room temperature. Then, $50 \mu \mathrm{L}$ $50 \mathrm{mM}$ Tris- $\mathrm{HCl}, \mathrm{pH} 7.5$, containing $2 \mathrm{mM} \mathrm{MnCl} 2$ was added to each lysate, and the enzyme was activated by heating the plates for $10 \mathrm{~min}$ at $56^{\circ} \mathrm{C}$. The lysates were transferred to centrifuge tubes $(25 \mu \mathrm{L} /$ tube $)$ containing $25 \mu \mathrm{L} 0.5 \mathrm{M} \mathrm{L}$-arginine, $\mathrm{pH} 9.7$, and substrate hydrolysis was performed by incubating the tubes for $60 \mathrm{~min}$ at $37^{\circ} \mathrm{C}$. The reaction was stopped with $400 \mu \mathrm{L}$ $\mathrm{H}_{2} \mathrm{SO}_{4}(96 \%) / \mathrm{H}_{3} \mathrm{PO}_{4}(85 \%) / \mathrm{H}_{2} \mathrm{O}(1 / 3 / 7, \mathrm{v} / \mathrm{v} / \mathrm{v})$. Then, 25 $\mu \mathrm{L} 9 \% \alpha$-isonitrosopropiophenone (dissolved in $100 \%$ ethanol) was added to the tubes, which were heated for $30 \mathrm{~min}$ at $95^{\circ} \mathrm{C}$. After cooling, $50 \mu \mathrm{L}$ of each reaction mixture was transferred to microplates in triplicate, and absorbance was measured at $540 \mathrm{~nm}$ with an ELISA reader (Multiskan II, MS). The concentration of urea was determined by comparison with a standard curve of 1.5 to $300 \mu \mathrm{g} / \mathrm{mL}$ urea.

\section{Cytokine determination}

The levels of IL-1a (Quantikine M murine; R\&D Systems; test sensitivity, $5 \mathrm{pg} / \mathrm{mL}$ ), IL-10 (Pharmingen, USA; test sensitivity, $30 \mathrm{pg} / \mathrm{mL}$ ) and TNF- $\alpha$ (DuoSet ELISA Kit; R\&D Systems, Inc.; test sensitivity, 62.5 pg/ $\mathrm{mL}$ ) were measured in macrophage supernatants according to manufacturer instructions. Absorbance was read at $450 \mathrm{~nm}$, with the wavelength of $540 \mathrm{~nm}$ used for correction. 


\section{Statistical analysis}

Data were analyzed with the GraphPad Prism software using the Student $t$-test to compare two groups. One-way ANOVA followed by the Bonferroni test was used for the comparison of more than two groups. Statistical significance was set at $P<0.05$.

\section{Results}

\section{iNOS and arginase activities in PMФ and BMMФ of young BALB/c mice}

The peritoneal and bone marrow-derived macrophages
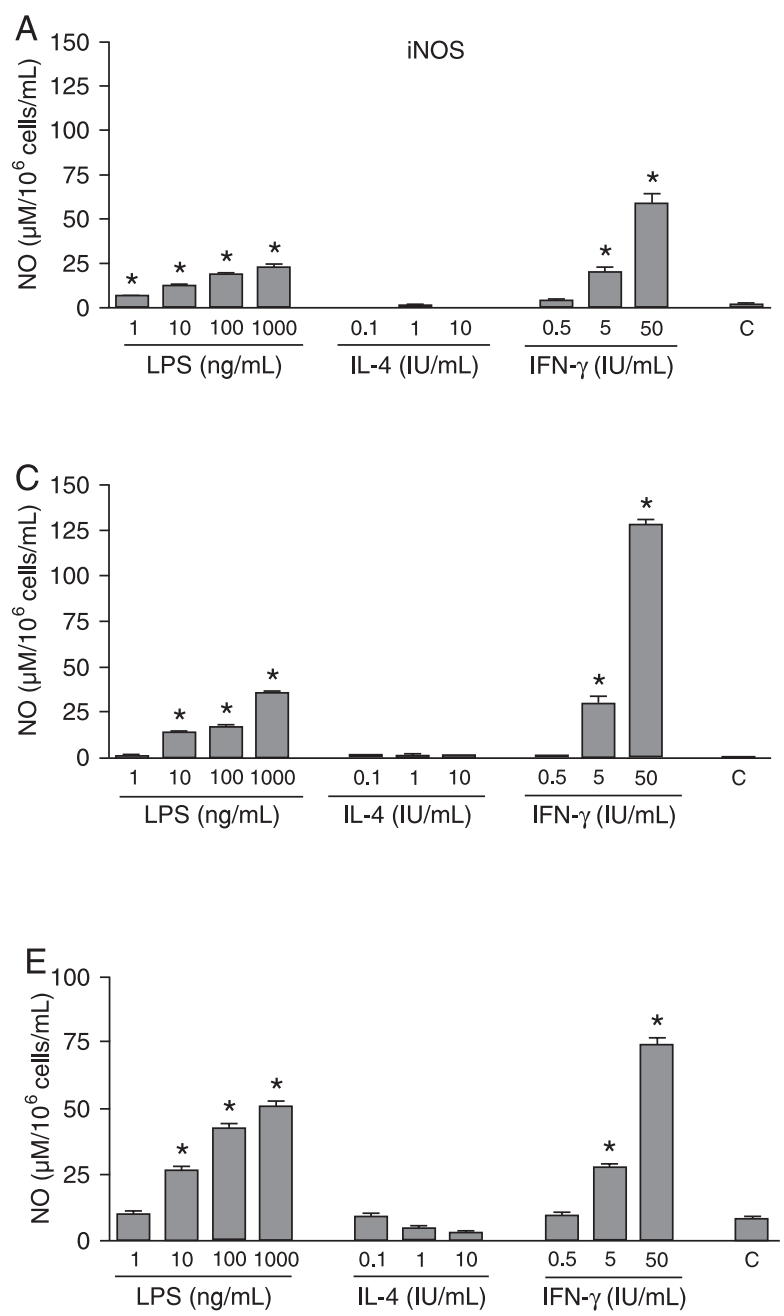

were cultured for $48 \mathrm{~h}$ with LPS, IFN-y and IL-4, alone or in combination. iNOS activity was measured on the basis of nitrite accumulation in the culture supernatants, and arginase activity was determined by measuring arginine-derived urea in the cell extracts.

LPS and IFN- $\gamma$ induced nitrite accumulation in the culture supernatants of naive and elicited $P M \Phi$ in a dosedependent manner (Figure 1, Panels A and C, respectively). Arginase activity was already present in the non-stimulated macrophages, since extracts obtained from these cells were able to convert L-arginine to urea (Figure 1, Panels B and D). The addition of IL-4 to peritoneal macrophage cultures
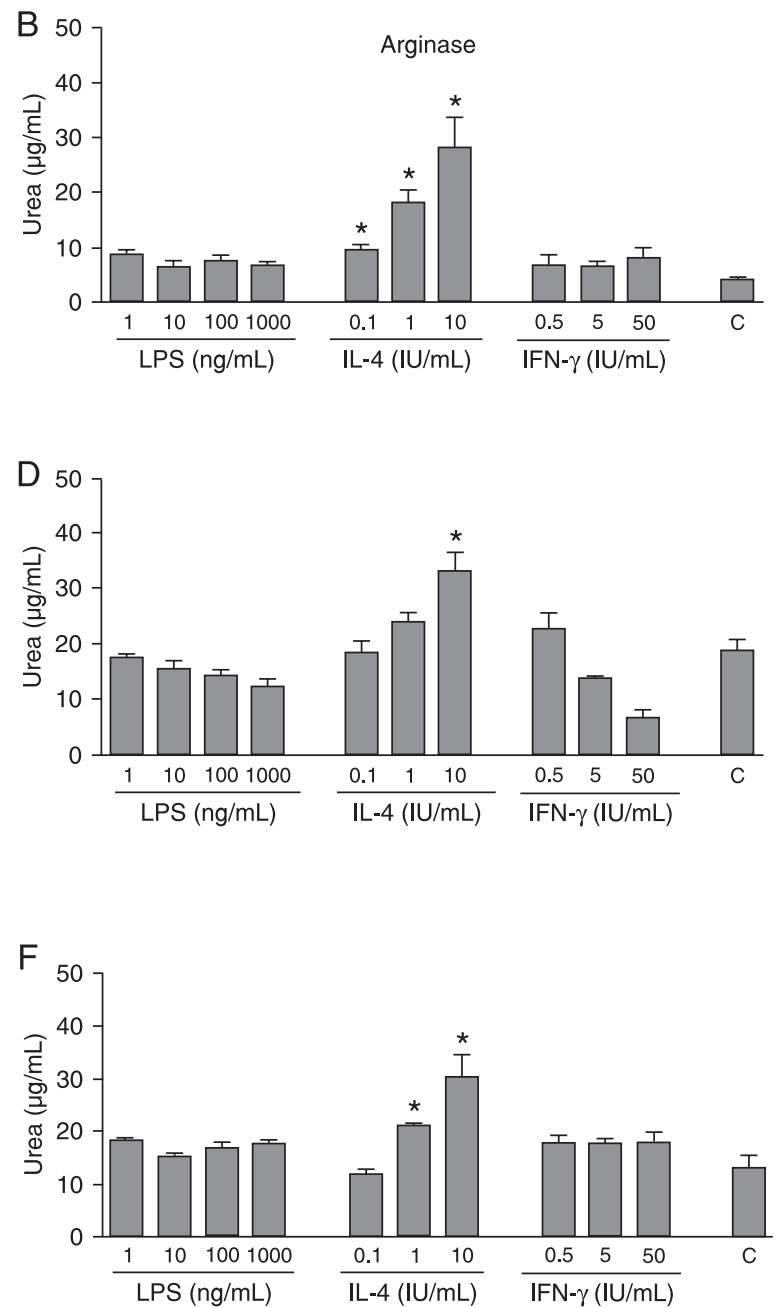

Figure 1. Inducible nitric oxide synthase (iNOS) and arginase activities in macrophages of young BALB/c mice: effects of lipopolysaccharide (LPS), interleukin-4 (IL-4) and interferon- $\gamma$ (IFN- $\gamma$ ). $A$ and $B$, Peritoneal macrophages from naive mice; $C$ and $D$, peritoneal macrophages from thioglycolate-elicited mice; $E$ and $F$, bone marrow-derived macrophages. Adherent cells from 6 mice per group were incubated in the presence of LPS $(1,10,100$, and $1000 \mathrm{ng} / \mathrm{mL})$, IL-4 $(0.1,1$, and $10 \mathrm{IU} / \mathrm{mL})$ or IFN-ץ $(0.5,5$, and $50 \mathrm{IU} / \mathrm{mL})$ for 48 h; all studies were conducted in triplicate. Cells of control groups (C) were incubated in the absence of stimuli. Nitrite was measured in the culture supernatants using Griess reagent, and arginase activity was determined in cell lysates on the basis of the amounts of urea produced from L-arginine. Bars indicate the means \pm SEM of nitrite (Panels A, C, and E) and urea (Panels B, D, and F) levels in three independent experiments. ${ }^{*} \mathrm{P} \leq 0.05$ compared to control (Student $t$-test). 
increased arginase expression in a dose-dependent manner, as observed by the increase in urea conversion rates in these extracts (Figure 1, Panel C), whereas no such results were obtained with the addition of LPS or IFN-Y (Figure 1, Panel D).

BMMФ cultured in the presence of LPS or IFN-y also produced elevated levels of NO (Figure 1, Panel E). The exposure of these macrophages to IL-4 also resulted in the elevation of their arginase activity (Figure 1, Panel F).

The treatment of cell monolayers with IL-4 simultaneously with LPS significantly reduced the production of $\mathrm{NO}$ in $\mathrm{PM} \Phi$ of naive mice but not of elicited mice (Figure 2, Panel A). Conversely, treatment with IL-4 parcialy reversed the inhibitory effect of LPS on arginase activity observed in elicited PMФ (Figure 2, Panel B). Treatment with IL-4 significantly reduced the LPS-induced NO production in BMMФ (Figure 2, Panel C), but had no effect on arginase activity when added to the cultures concomitantly with LPS (Figure 2, Panel D).

\section{Effects of phagocytosis on iNOS and arginase activities in peritoneal macrophages of young mice}

To investigate the role of phagocytosis in arginase activity and NO production, adherent cells from BALB/c and C57BL/6 mice were treated with three different kinds of particles: L. major, C3b opsonized zymosan and apoptotic lymphocytes. Figure 3 illustrates the results obtained in these experiments. Phagocytosis of zymosan particles resulted in an elevation of arginase activity in peritoneal macrophage lysates of both naive and elicited BALB/c mice (Figure 3, Panels $B$ and $H$, respectively), as well as those from elicited C57BL/6 mice (Figure 3, Panel K). The phagocytosis of apoptotic lymphocytes also increased arginase activity in elicited PM $\Phi$ of both BALB/C and C57BL/6 mice, but not in those of naive mice (Figure 3, Panels I and L, respectively). Treatment with $L$. major did not alter the arginase levels in
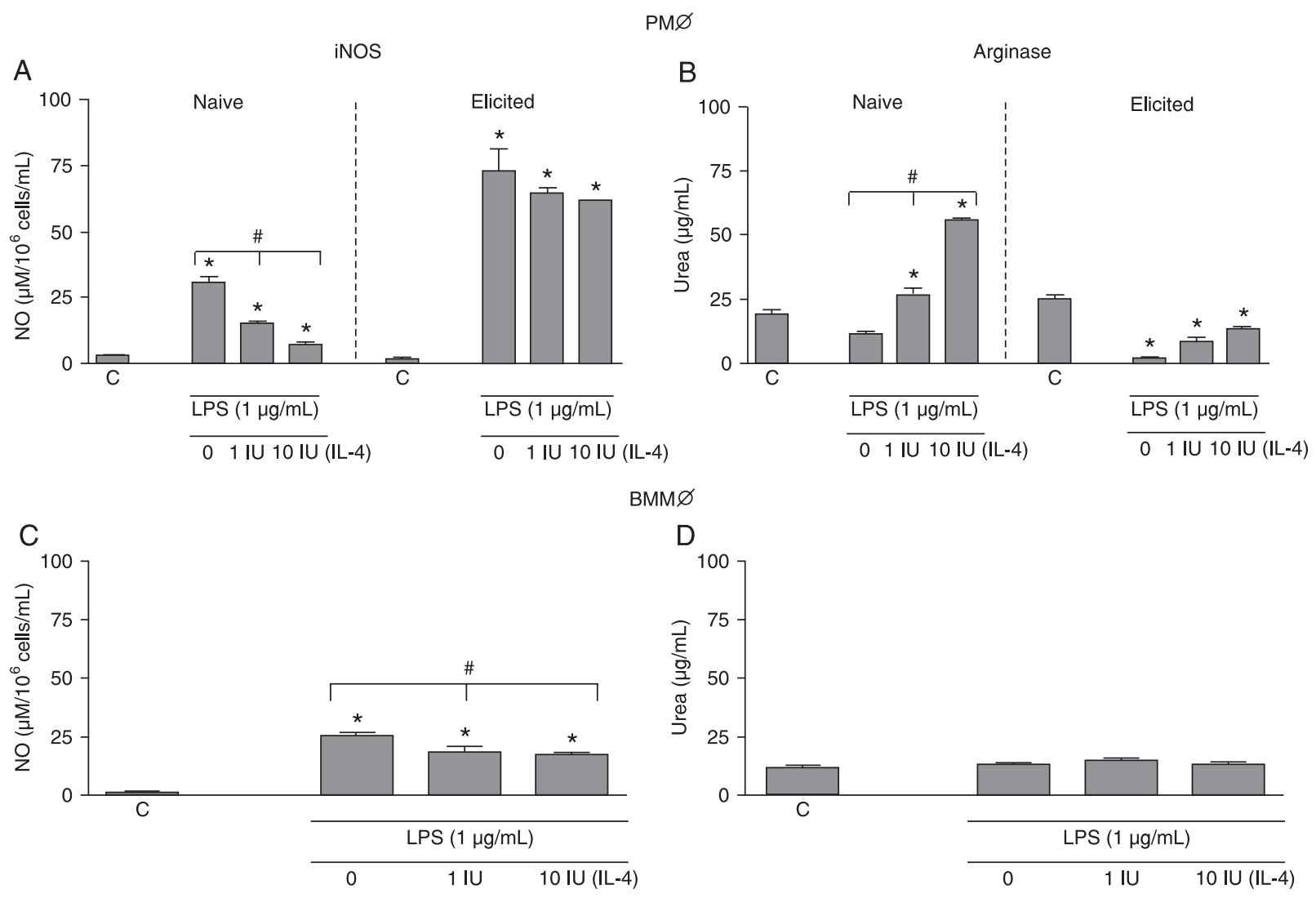

BMM $\varnothing$

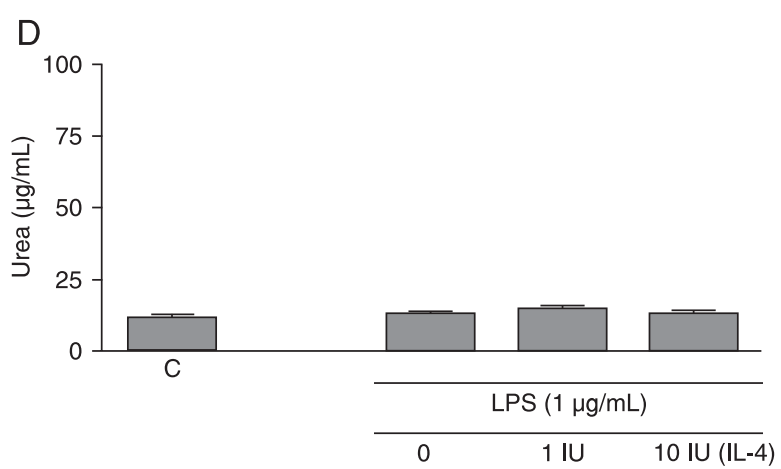

Figure 2. Effects of IL-4 on LPS-induced inducible nitric oxide synthase (iNOS) and arginase activities in macrophages of young $B A L B / c$ mice ( $N=6$ per group). Naive and elicited peritoneal macrophages (PMФ) and bone marrow-derived macrophages (BMM $\Phi$ ) from young BALB/c mice were incubated with lipopolysaccharide (LPS; $1 \mu \mathrm{g} / \mathrm{mL}$ ) in the presence or absence of interleukin-4 (IL-4; 1 or $10 \mathrm{IU} / \mathrm{mL}$ ) for $48 \mathrm{~h}$, at $37^{\circ} \mathrm{C}$, in $5 \% \mathrm{CO}_{2}$. Cells of the control groups (C) were incubated in the absence of stimuli. Nitrite was measured in the culture supernatants using Griess reagent, and arginase activity was determined in cell lysates based on the amounts of urea produced from L-arginine. All studies were conducted in triplicate. Bars indicate the means \pm SEM of nitrite (Panels A, B) and urea (Panels C, D) levels in three independent experiments. ${ }^{*} \mathrm{P} \leq 0.05$ (comparison was carried out by the Student $t$-test) and ${ }^{\#} \mathrm{P} \leq$ 0.05 (comparison was carried out by ANOVA followed by the Bonferroni post-test). 

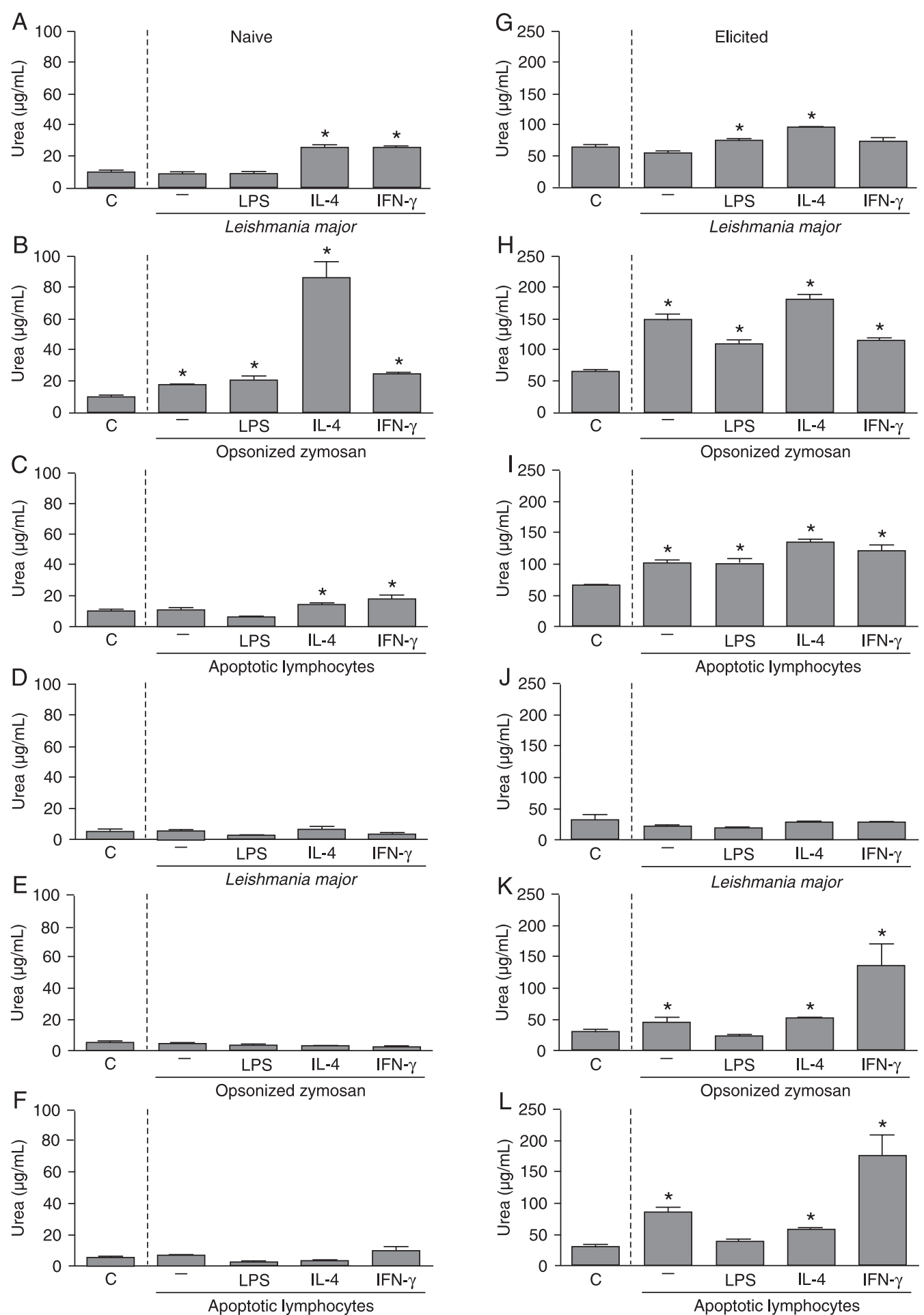

Figure 3. Effects of phagocytosis on arginase activity in peritoneal macrophages of mice ( $\mathrm{N}=6$ per group). A, B, C, Naive BALB/C mice; $D, E, F$, naive C57BL/6 mice; $G, H$, I, elicited BALB/c mice; J, $K$, L, elicited C57BL/6 mice. Adherent peritoneal cells were incubated with lipopolysaccharide (LPS; $100 \mathrm{ng} / \mathrm{mL}$ ), interleukin-4 (IL-4; $4 \mathrm{IU} / \mathrm{mL}$ ) or interferon- $\gamma\left(\mathrm{IFN}-\mathrm{\gamma}, 5 \mathrm{IU} / \mathrm{mL}\right.$ ) for $18 \mathrm{~h}$, at $37^{\circ} \mathrm{C}$, in $5 \%$ $\mathrm{CO}_{2}$. Cells of the control groups (C) were incubated in the absence of stimuli. After removal of the stimuli, cells were incubated with Leishmania major $\left(3 \times 10^{6}\right.$ cells $\left./ \mathrm{mL}\right)$, C3b opsonized zymosan $\left(5 \times 10^{6}\right.$ yeasts $\left./ \mathrm{mL}\right)$ or apoptotic lymphocytes $\left(5 \times 10^{6} \mathrm{cells} / \mathrm{mL}\right)$ for $3 \mathrm{~h}$. Particles were then removed by washing, and the plates were re-incubated for $48 \mathrm{~h}$. Arginase activity was determined in cell lysates on the basis of the amount of urea produced from L-arginine. All studies were conducted in triplicate. Bars indicate the means \pm SEM of urea levels obtained in three independent experiments. ${ }^{*} \mathrm{P} \leq 0.05$ compared to control (Student $t$-test). 
adherent cells of either BALB/c (Figure 3, Panels A and G) or C57BL6 mice (Figure 3, Panels D and J).

The pretreatment of adherent peritoneal cells with a suboptimal dose of IL-4 before the addition of phagocytic stimuli resulted in a more marked effect on arginase activity in $Р M Ф$ lysates obtained from BALB/c mice (Figure 3, Panels $A, B, C$ and $G, H, I$ ), whereas such pretreatment had no effect on arginase activity in those from C57BL/6 mice. Conversely, pretreatment with a suboptimal dose of IFN-Y resulted in more elevated arginase activity in $\mathrm{PM} \Phi$ lysates obtained from C57BL/6 after phagocytosis of zymosan and apoptotic lymphocytes (Figure 3, Panels K and L). NO production was not observed in macrophage supernatants after phagocytosis of the particles used here.

\section{iNOS and arginase activity in peritoneal and bone marrow-derived macrophages of old BALB/c mice}

iNOS and arginase activities were investigated comparatively in $\mathrm{PM} Ф$ and $B M M \Phi$ from both old (72 weeks of age) and young ( 8 weeks of age) BALB/c mice. Figure 4 illustrates the results obtained in these experiments. $P M \Phi$ from naive old mice exhibited a diminished production of NO in response to both LPS and IFN-Y (Figure 4, Panel A), and lower arginase activity after treatment with LPS and IL-4 (Figure 4, Panel $B)$ than did those from young mice. Thyoglycolate-elicited $\mathrm{PM} \Phi$ isolated from old mice also revealed slightly lower NO production following stimulation with LPS than did those from young mice. IFN- $\mathrm{Y}$ induced similar levels of $\mathrm{NO}$ in elicited PMФ of both young and old mice (Figure 4, Panel A). The arginase activity in response to IL-4 increased equally in both naive and thyoglycolate-elicited $\mathrm{PM} \Phi$ of young mice (Figure 4, Panel B), and basal levels of arginase activity were observed in naive $\mathrm{PM} \Phi$ of old mice stimulated with IL-4. ВМMФ obtained from both young and old mice were equally capable of producing NO in response to IFN- $\mathrm{\gamma}$, but old mice were more responsive to LPS (Figure 4, Panel C). Arginase activity was elevated only in $B M M \Phi$ from old mice stimulated with IL-4 (Figure 4, Panel D).
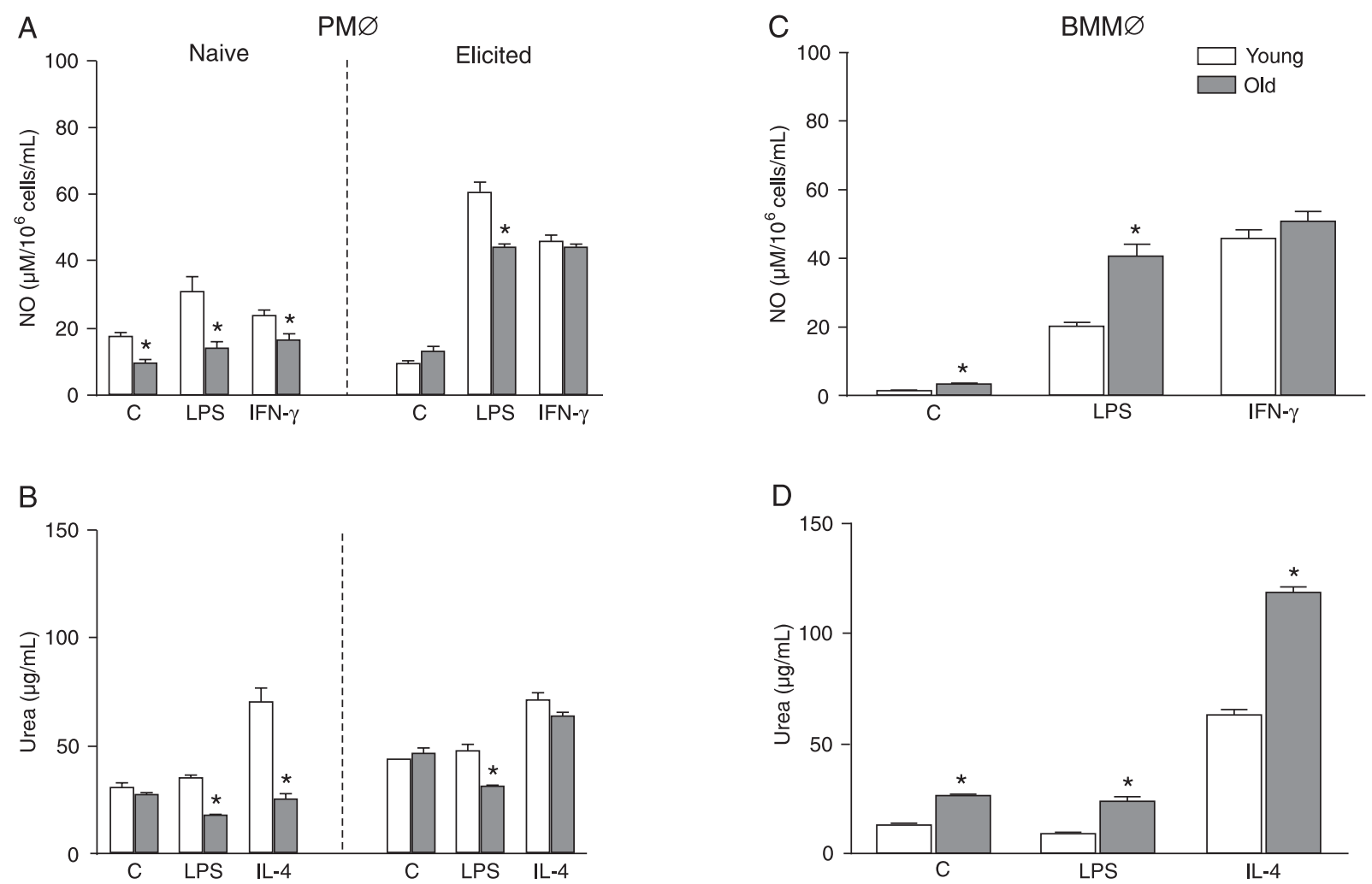

Figure 4. Aging affects inducible nitric oxide synthase (iNOS) and arginase activities in macrophages of BALB/c mice. Naive mice $(N=14)$ were the source of naive peritoneal macrophages and bone marrow-derived macrophages. Elicited macrophages were obtained from mice $(\mathrm{N}=6)$ injected 4 days previously with thioglycolate medium. Young and old mice were used at the ages of 8 and 72 weeks, respectively. Adherent cells were cultured in the presence of lipopolysaccharide (LPS; $1 \mu \mathrm{g} / \mathrm{mL}$ ), interleukin-4 (IL-4; 40 IU/mL) or interferon-y (IFN- $\gamma ; 50 \mathrm{IU} / \mathrm{mL}$ ) for $48 \mathrm{~h}$ at $37^{\circ} \mathrm{C}$, in $5 \% \mathrm{CO}_{2}$. Cells of the control groups (C) were incubated in the absence of stimuli. Nitrite was measured in the culture supernatants using a Griess reagent, and arginase activity was determined in cell lysates based on the amounts of urea converted from L-arginine. All studies were conducted in triplicate. Bars indicate the means \pm SEM of nitrite (Panels A, C) or urea (Panels B, D) levels in three independent experiments. ${ }^{*} \mathrm{P} \leq 0.05$ compared to control (Student $t$-test). 


\section{Cytokine production}

IL-1, IL-10 and TNF- $\alpha$ were measured by ELISA in supernatants of $Р М Ф$ and $В M M \Phi$ obtained from both young and old BALB/c mice, cultured in the presence of LPS. As depicted in Figure 5, peritoneal macrophages from both naive and elicited mice were capable of producing IL-1 and TNF- $\alpha$ when stimulated by LPS. However, elicited PM $\Phi$ from older mice showed a more elevated production of IL-1 (Figure 5, Panel A), whereas those from younger mice produced more TNF- $\alpha$ (Figure 5, Panel B). The production of IL-10, on the
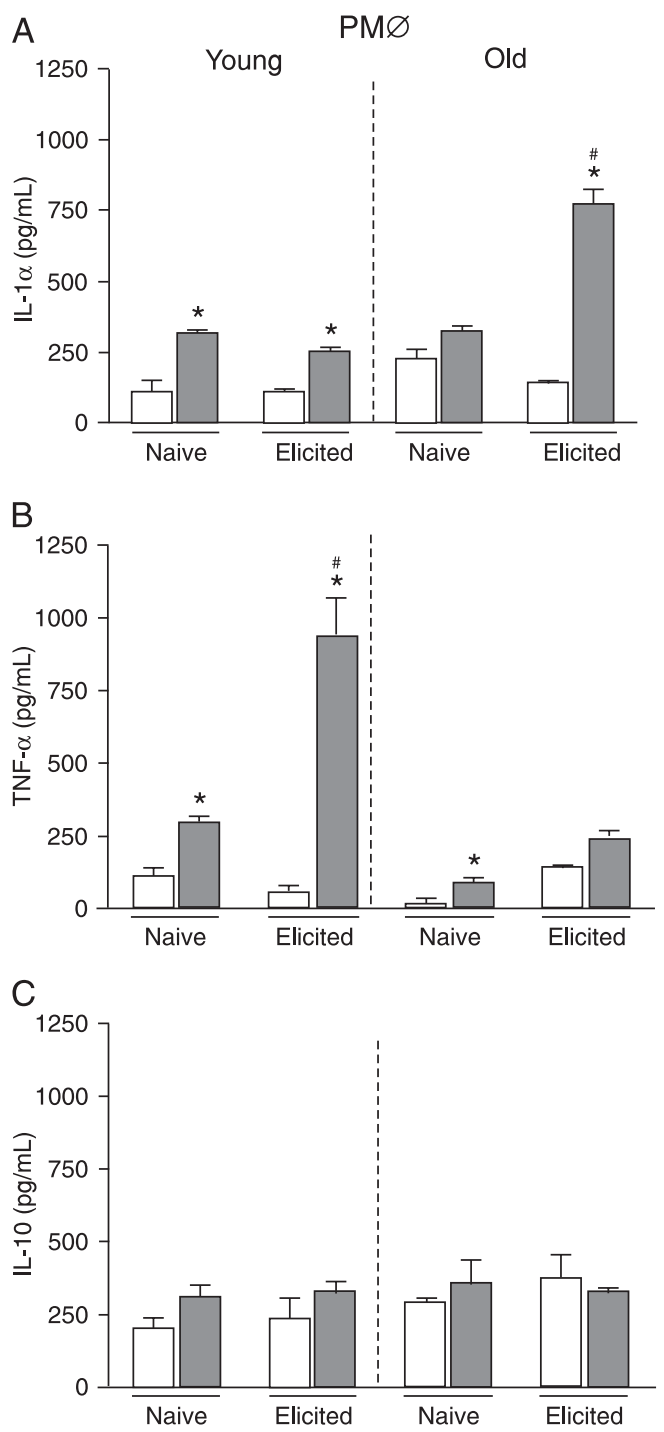

other hand, was not affected by LPS stimulation, independent of the age of the mice (Figure 5, Panel C).

Stimulation of BMM $\Phi$ with LPS led to production of only TNF- $\alpha$, with macrophages from aged mice showing the highest levels of this cytokine (Figure 5, Panel E). As shown in Panel D, IL-1 was not produced by BMM $\Phi$.

\section{Discussion}

Aging is accompanied by a low-grade elevation in the

D

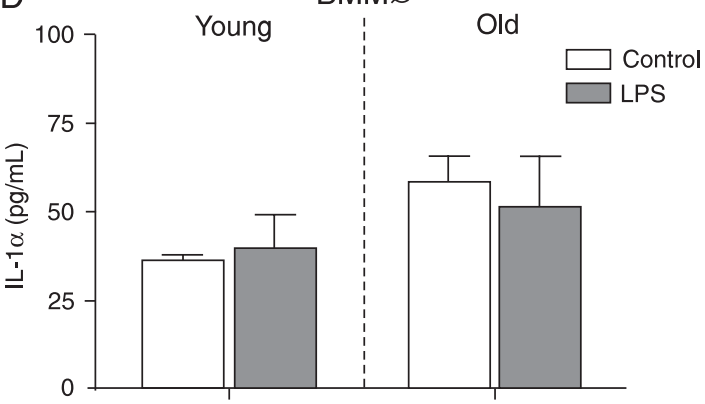

$\mathrm{E}$

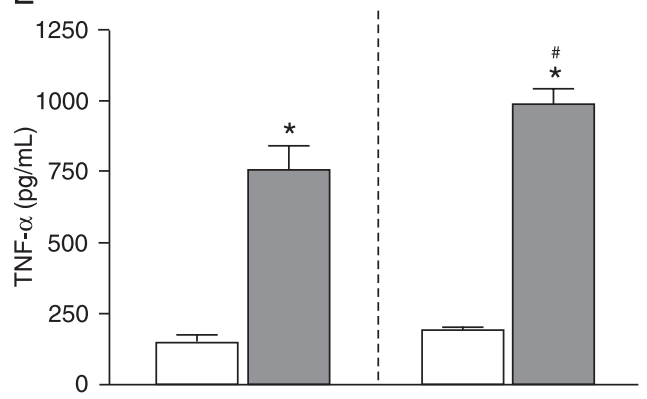

$\mathrm{F}$

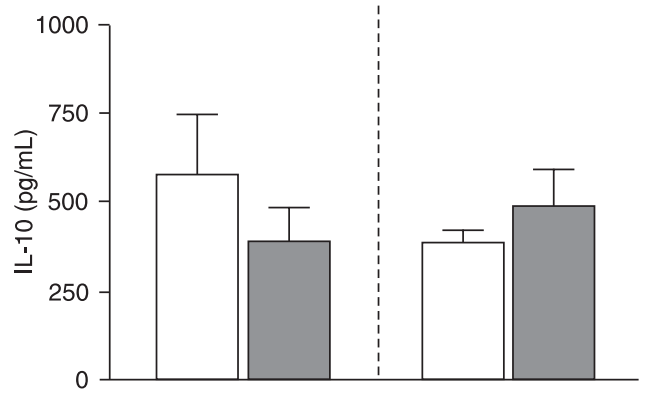

Figure 5. Aging affects cytokine production in peritoneal macrophages and bone marrow-derived macrophages of $B A L B / c$ mice $(N=$ 6 per group). Naive and thioglycolate-elicited peritoneal macrophages (Panels A, B, and C) and bone marrow-derived macrophages (Panels D, E, and F) from young and old mice were prepared and cultured as described in the legend to Figure 4. The culture supernatants were used for the detection of interleukin-1 $\alpha$ (IL-1 $\alpha$; Quantikine M murine; test sensitivity, $5 \mathrm{pg} / \mathrm{mL}$ ), tumor necrosis factor- $\alpha$ (TNF-a; DuoSet ELISA Kit; test sensitivity, $62.5 \mathrm{pg} / \mathrm{mL}$ ) and interleukin-10 (IL-10; Pharmingen; test sensitivity, $30 \mathrm{pg} / \mathrm{mL}$ ). All studies were conducted in triplicate. Bars indicate the means \pm SEM of the respective cytokines detected in three independent experiments. ${ }^{*} \mathrm{P} \leq 0.05$ compared to control (Student $t$-test). 
concentrations of certain circulating inflammatory markers such as cytokines and their receptors, chemokines, and acute phase proteins (25). This state, also called "Inflammaging" (26), correlates with neurological conditions such as Alzheimer's disease and various cardiovascular diseases such as atherosclerosis (for a review, see Ref. 2).

In the present study, we analyzed the production of iNOS and arginase enzymes in $\mathrm{PM} \Phi$ and $B M M \Phi$ from young and old BALB/c mice, as well as cytokine production by these cells. Initially, we evaluated the most favorable conditions for the induction of iNOS and arginase activity in PMФ and BMМФ from young mice stimulated with LPS, either alone or in combination with IFN-y or IL-4. NO accumulated in a dose-dependent manner in both types of macrophages treated with LPS+IFN- $\gamma$, whereas arginase activity increased only in IL-4-stimulated cells. Moreover, IL-4 inhibited the NO production induced by LPS, thus confirming reports in the literature $(24,27-28)$. LPS, however, did not increase arginase activity in either type of macrophages obtained from BALB/c mice, nor was IL-4 capable of reversing the inhibition of arginase activity induced by LPS. Our results partially contradict those reported by Mills et al. (29), who showed that LPS increased the metabolism of L-arginine to ornithine/urea in resident $\mathrm{PM} \Phi$ from $B A L B / c$ mice at doses as low as $1 \mathrm{ng} / \mathrm{mL}$, whereas macrophages from C57BL/6 mice metabolized L-arginine mainly via iNOS. In the present study, however, neither resident nor elicited $\mathrm{PMФ} \mathrm{or} \mathrm{ВММФ}$ from $B A L B / c$ mice significantly elevated the conversion rate of L-arginine to urea when LPS was used at doses from 1 to $1000 \mathrm{ng} / \mathrm{mL}$. However, the concept of M-2 macrophages proposed by Mills et al. (29) is still applicable to BALB/c macrophages because of the clear contrasting effects of Th1 and Th2 cytokines on L-arginine metabolism in the macrophages of these mice.

Moreover, we tested the effects of phagocytosis on both arginase and iNOS activity in PMФ from young BALB/C and C57BL/6 mice. Adherent cells were incubated with opsonized zymosan, L. major, and apoptotic lymphocytes, so that different surface receptors would be used for the internalization of the particles. Opsonized zymosan, a complement C3bi-coated insoluble polysaccharide, binds to its specific receptor of the $\beta 2$ integrin family (CR3, CD11b/ CD18) to trigger cytoskeletal reorganization (30) and the activation of many important cell functions, including phagocytosis, superoxide production, and chemotaxis (31). On the other hand, binding of apoptotic cells to the phosphatidylserine receptor on phagocytes stimulates cell internalization and simultaneous secretion of immunosuppressive cytokines (32). However, the initial process of Leishmania internalization remains unknown, and recent literature data have ruled out the mannose receptor as the way by which the parasite enters the macrophages (33). In the present study, we observed that NO was not produced in any of these situations; hence, we concluded that BALB/c and C57BL/6 PMФ are unable to metabolize L-arginine via iNOS following phagocytosis of such different particles, even in the presence of suboptimal doses of LPS or IFN-y. Arginase activity, however, was affected by phagocytosis and was dependent on the type of stimuli and strain of macrophage donors. In this regard, macrophages from BALB/c showed higher arginase activity after phagocytosis than those from C57BL/6 mice. Pretreatment with suboptimal doses of IL-4 increased the conversion of $L$-arginine to urea in both naive and elicited BALB/c phagocytic cells, whereas for C57BL/6 macrophages, such treatment was only effective for elicited cells and for the phagocytosis of opsonized zymosan and apoptotic lymphocytes. Similarly, Iniesta et al. (18) reported that BMMФ from BALB/c mice treated with Th2 type cytokines (IL-4, IL-10, and TGF- $\beta$ ) before incubation with $L$. major presented higher levels of arginase activity than did C57BL/6 mice. Surprisingly, the suboptimal doses of IFN-y induced an increase in arginase activity in the PMФ of both BALB/c and C57BL/6 mice that phagocytized opsonized zymosan and apoptotic lymphocytes.

The cellularity in peritoneal washings from old BALB/C mice was higher than that observed in younger ones (data not shown). However, the adherent cells of young mice showed greater responses to LPS than those of older mice, as indicated by the amounts of NO and TNF- $\alpha$ measured in the cultures. On the other hand, ВMMФ from old mice exposed to LPS showed the highest levels of iNOS. In contrast, when the stimulus was IFN- $\gamma$, the differences as a function of age and of macrophage source were no longer observed. The responses to the anti-inflammatory cytokine IL-4 followed the same pattern as described for LPS, with the younger cells presenting the more elevated levels of arginase activity. Our results are similar to those reported by Kissin et al. (34) since stimulation of $P M \Phi$ with LPS led to a decrease in iNOS activity in older mice. Chen et al. (35), however, reported an increase in iNOS expression in older mice stimulated with LPS. Such discrepancies may be related to the specific experimental model, including factors such as mouse lineage, age range studied and inflammatory stimuli used. Moreover, the literature comparing iNOS and arginase activity in BMMФ from young and old mice is very limited; such cells have been subjected to more studies involving their antigen-presenting activity, than their response to inflammatory agents (36).

Age also proved to be critical for the production of inflammatory cytokines by PMФ stimulated with LPS. Cells elicited from older mice produced larger amounts of the pro-inflammatory IL-1 $\alpha$, whereas those from younger mice produced more TNF- $\alpha$. IL-10 levels of older and younger mice were not changed by LPS treatment in PM $\Phi$ or ВММФ. However, macrophages differentiated in vitro presented more elevated constitutive levels of IL-10 than those from the peritoneum, a characteristic that agrees with the tolerant profile of these immature cells (37). The only pro-inflammatory cytokine produced by $\mathrm{BMM} \Phi$ in response to LPS was TNF- $\alpha$, with the older mice producing more than 
the younger ones. Although some studies have shown an elevation of inflammatory markers in older individuals that correlate with age-related diseases and increased risk of mortality, literature data are inconclusive about this matter in both animal models and human subjects, with some reports showing an age-associated decrease in IL-1 and TNF- $\alpha$ levels and others suggesting an elevation of proand anti-inflammatory cytokines after LPS stimulation of macrophages (for a review, see Ref. 38).

The results obtained in the present study indicate that the responses of macrophages from young and old animals

\section{References}

1. Panda A, Arjona A, Sapey E, Bai F, Fikrig E, Montgomery $\mathrm{RR}$, et al. Human innate immunosenescence: causes and consequences for immunity in old age. Trends Immunol 2009; 30: 325-333.

2. Kovacs EJ, Palmer JL, Fortin CF, Fulop T Jr, Goldstein DR, Linton PJ. Aging and innate immunity in the mouse: impact of intrinsic and extrinsic factors. Trends Immunol 2009; 30: 319-324.

3. Shaw AC, Joshi S, Greenwood H, Panda A, Lord JM. Aging of the innate immune system. Curr Opin Immunol 2010; 22: 507-513.

4. Reis e Sousa C. Activation of dendritic cells: translating innate into adaptive immunity. Curr Opin Immunol 2004; 16 : 21-25.

5. Green SJ, Nacy CA, Meltzer MS. Cytokine-induced synthesis of nitrogen oxides in macrophages: a protective host response to Leishmania and other intracellular pathogens. J Leukoc Biol 1991; 50: 93-103.

6. Moncada S, Palmer RM, Higgs EA. Biosynthesis of nitric oxide from L-arginine. A pathway for the regulation of cell function and communication. Biochem Pharmacol 1989; 38: 1709-1715.

7. Moncada S. Nitric oxide: discovery and impact on clinical medicine. J R Soc Med 1999; 92: 164-169.

8. Stuehr DJ, Marletta MA. Induction of nitrite/nitrate synthesis in murine macrophages by BCG infection, lymphokines, or interferon-gamma. J Immunol 1987; 139: 518-525.

9. Marletta MA, Yoon PS, lyengar R, Leaf CD, Wishnok JS. Macrophage oxidation of L-arginine to nitrite and nitrate: nitric oxide is an intermediate. Biochemistry 1988; 27 : 87068711.

10. Green SJ, Meltzer MS, Hibbs JB Jr, Nacy CA. Activated macrophages destroy intracellular Leishmania major amastigotes by an L-arginine-dependent killing mechanism. $J$ Immunol 1990; 144: 278-283.

11. Liew FY, Millott S, Parkinson C, Palmer RM, Moncada S. Macrophage killing of Leishmania parasite in vivo is mediated by nitric oxide from L-arginine. J Immunol 1990; 144: 4794-4797.

12. Roach TI, Kiderlen AF, Blackwell JM. Role of inorganic nitrogen oxides and tumor necrosis factor alpha in killing Leishmania donovani amastigotes in gamma interferonlipopolysaccharide-activated macrophages from Lshs and Lshr congenic mouse strains. Infect Immun 1991; 59: 39353944. may vary according to the microenvironment and to the stimuli to which they are subjected, without necessarily displaying a constitutive inflammatory profile. However, we also speculate that the changes in innate immunity observed here may contribute to the damages associated with the aging process.

\section{Acknowledgments}

\author{
Research supported by FAPESP (\#2003/03289-8).
}

13. Bogdan C, Rollinghoff M, Diefenbach A. Reactive oxygen and reactive nitrogen intermediates in innate and specific immunity. Curr Opin Immunol 2000; 12: 64-76.

14. Morris SM Jr. Regulation of enzymes of urea and arginine synthesis. Annu Rev Nutr 1992; 12: 81-101.

15. Blantz RC, Satriano J, Gabbai F, Kelly C. Biological effects of arginine metabolites. Acta Physiol Scand 2000; 168: 2125.

16. Yu H, lyer RK, Yoo PK, Kern RM, Grody WW, Cederbaum $\mathrm{SD}$. Arginase expression in mouse embryonic development. Mech Dev 2002; 115: 151-155.

17. Cederbaum SD, Yu H, Grody WW, Kern RM, Yoo P, Iyer RK. Arginases I and II: do their functions overlap? Mol Genet Metab 2004; 81 (Suppl 1): S38-S44.

18. Iniesta V, Gomez-Nieto LC, Molano I, Mohedano A, Carcelen $\mathrm{J}$, Miron $\mathrm{C}$, et al. Arginase I induction in macrophages, triggered by Th2-type cytokines, supports the growth of intracellular Leishmania parasites. Parasite Immunol 2002; 24: 113-118.

19. Morris SM Jr, Kepka-Lenhart D, Chen LC. Differential regulation of arginases and inducible nitric oxide synthase in murine macrophage cells. Am J Physiol 1998; 275: E740E747.

20. Sonoki T, Nagasaki A, Gotoh T, Takiguchi M, Takeya M, Matsuzaki $\mathrm{H}$, et al. Coinduction of nitric-oxide synthase and arginase I in cultured rat peritoneal macrophages and rat tissues in vivo by lipopolysaccharide. J Biol Chem 1997; 272: 3689-3693.

21. Munder M, Eichmann K, Moran JM, Centeno F, Soler G, Modolell M. Th1/Th2-regulated expression of arginase isoforms in murine macrophages and dendritic cells. J Immunol 1999; 163: 3771-3777.

22. Cecilio CA, Costa EH, Ucelli P, Chaves CA, Toffoli MC, Flores $\mathrm{CA}$, et al. The neutrophil migration induced by tumour necrosis factor alpha in mice is unaffected by glucocorticoids. Mediators Inflamm 1997; 6: 46-52.

23. Fadok VA, Voelker DR, Campbell PA, Cohen JJ, Bratton DL, Henson PM. Exposure of phosphatidylserine on the surface of apoptotic lymphocytes triggers specific recognition and removal by macrophages. J Immunol 1992; 148: 2207-2216.

24. Corraliza IM, Campo ML, Soler G, Modolell M. Determination of arginase activity in macrophages: a micromethod. $J$ Immunol Methods 1994; 174: 231-235.

25. Franceschi C, Bonafe M, Valensin S, Olivieri F, De Luca M, Ottaviani $\mathrm{E}$, et al. Inflamm-aging. An evolutionary perspec- 
tive on immunosenescence. Ann N Y Acad Sci 2000; 908: 244-254.

26. De Martinis M, Franceschi C, Monti D, Ginaldi L. Inflammageing and lifelong antigenic load as major determinants of ageing rate and longevity. FEBS Lett 2005; 579: 20352039.

27. Corraliza IM, Soler G, Eichmann K, Modolell M. Arginase induction by suppressors of nitric oxide synthesis (IL-4, IL-10 and PGE2) in murine bone-marrow-derived macrophages. Biochem Biophys Res Commun 1995; 206: 667-673.

28. Modolell M, Corraliza IM, Link F, Soler G, Eichmann K. Reciprocal regulation of the nitric oxide synthase/arginase balance in mouse bone marrow-derived macrophages by $\mathrm{TH} 1$ and TH2 cytokines. Eur J Immunol 1995; 25: 1101-1104.

29. Mills CD, Kincaid K, Alt JM, Heilman MJ, Hill AM. M-1/M-2 macrophages and the Th1/Th2 paradigm. J Immunol 2000; 164: 6166-6173.

30. Le Cabec V, Carreno S, Moisand A, Bordier C, MaridonneauParini I. Complement receptor 3 (CD11b/CD18) mediates type I and type II phagocytosis during nonopsonic and opsonic phagocytosis, respectively. J Immunol 2002; 169: 2003-2009.

31. Babior BM. NADPH oxidase: an update. Blood 1999; 93:
$1464-1476$

32. Somersan S, Bhardwaj N. Tethering and tickling: a new role for the phosphatidylserine receptor. J Cell Biol 2001; 155: 501-504.

33. Akilov OE, Kasuboski RE, Carter CR, McDowell MA. The role of mannose receptor during experimental leishmaniasis. J Leukoc Biol 2007; 81: 1188-1196.

34. Kissin E, Tomasi M, Cartney-Francis N, Gibbs CL, Smith PD. Age-related decline in murine macrophage production of nitric oxide. J Infect Dis 1997; 175: 1004-1007.

35. Chen LC, Pace JL, Russell SW, Morrison DC. Altered regulation of inducible nitric oxide synthase expression in macrophages from senescent mice. Infect Immun 1996; 64: 4288-4298.

36. Plackett TP, Boehmer ED, Faunce DE, Kovacs EJ. Aging and innate immune cells. J Leukoc Biol 2004; 76: 291-299.

37. Lin KW, Jacek T, Jacek R. Dendritic cells heterogeneity and its role in cancer immunity. J Cancer Res Ther 2006; 2: 3540.

38. Bruunsgaard $H$, Pedersen $M$, Pedersen BK. Aging and proinflammatory cytokines. Curr Opin Hematol 2001; 8: 131-136. 